\title{
Use of Tranexamic Acid (TXA) on reducing blood loss during scoliosis surgery in Chinese adolescents
}

\author{
Bobby K. W. Ng ${ }^{1,3^{*}}$, WW Chau ${ }^{1}$, Alec L. H. Hung ${ }^{1}$, Anna CN Hui ${ }^{2}$, Tze Ping Lam ${ }^{1}$ and Jack C. Y. Cheng ${ }^{1}$
}

\begin{abstract}
Background: Many reports had been received on the application of antifibrinolytic medications on spinal corrective surgery and the surgical outcome evaluations of its efficacy on reducing blood loss. This study aimed to assess the efficacy of tranexamic acid (TXA) in reducing operative blood loss during posterior spinal fusion for the treatment of severe adolescent idiopathic scoliosis (AIS).
\end{abstract}

Methods: A retrospective cohort study was carried out on $90($ TXA $=55$, Control $=35)$ AIS girls undergoing posterior spinal surgery. Patients in TXA group used TXA as an antifibrinolytic agent to reduce blood loss, while control group did not. Blood loss, haemoglobin change and amount of blood transfused was estimated from intraoperative measurement by anaesthesiologists. Demographics were compared using Student's T-test or Chi-square test where appropriate. Linear regression modelling was carried out between the use of TXA and total blood loss with controlling of confounding factors.

Results: Mean age and mean maximum major curve were 15.2 and $73^{\circ}$, and 15.3 and $63^{\circ}$ in TXA and control groups respectively. TXA group showed significantly less intra-operative blood loss than the control group from intraoperative measurement $(1.8 \mathrm{~L}$ vs. $3.9 \mathrm{~L}, p<0.01)$ and volume of cell saver blood transfused back to patients $(0.6 \mathrm{~L}$ vs. $1.7 \mathrm{~L}, p<0.01)$. TXA group also showed significantly shorter total time taken for surgery (437 min vs. $502 \mathrm{~min}, p<0.01$ ), and total blood loss per surgical segment level ( $0.1 \mathrm{~L}$ vs. $0.3 \mathrm{~L}, p<0.01)$. Regression models showed that the use of TXA decreased total blood loss by $794.3 \mathrm{ml}$ after adjusting for maximum major curve, age, number of segments fused, bone graft, clotting capability, and infusion of coagulation factors.

Conclusions: Patients undergoing posterior spinal corrective surgery with the use of TXA showed much reduced total blood loss, reduced use of transfused blood, much less cell saver blood transfused back to the patient. The total blood loss was decreased by after using TXA after controlling for maximum major curve, age, surgical parameters, clotting capability, and infusion of coagulation factors.

Keywords: Use of tranexamic acid at surgery in AIS

\section{Background}

Reconstructive spinal surgeries have been associated with large blood losses which is a common potential cause of morbidity and could subject to known risk of blood transfusions including blood-borne disease transmission, increased incidence of wound infections, haemolytic and

\footnotetext{
* Correspondence: bobng@ort.cuhk.edu.hk

'Department of Orthopaedics \& Traumatology, Chinese University of Hong Kong, Shatin, Hong Kong

${ }^{3}$ Department of Orthopaedics and Traumatology, The Chinese University of Hong Kong, Prince of Wales Hospital, Shatin, N.T., Hong Kong

Full list of author information is available at the end of the article
}

nonhaemolytic transfusion reactions. Despite interventions such as proper patient positioning on the operating room table, pharmaceutical muscle paralysis to decrease intra-abdominal pressure, intraoperative blood salvaging, and controlled hypotensive anaesthesia, blood losses of up to $3 \mathrm{l}$ can still be expected during some frequently performed procedures in spinal surgeries [1-4]. Therefore, any reduction in blood loss and the requirement for patient exposure to homologous blood products would be beneficial. 
Since the 1990s, intraoperative administration of antifibrinolytics (tranexamic acid, aprotinin, and e-aminocaproic acid) has gained popularity [5-13]. Antifibrinolytic medications have been applied during cardiac, total joint arthroplasty, and spine surgery with positive effect on blood loss without apparent increase in the risk of postoperative complications as shown by previous studies [7, 10, 12, 14-16]. Tranexamic acid (trans-4-aminomethyl-cyclohexane-1-carboxylic acid, TXA) is a synthetic lysine analogue and exerts its antifibrinolytic effect through the reversible blockade of lysine binding sites on plasminogen molecules. TXA is similar to e-aminocaproic acid but is considered to have 6 to 10 times of the potency in-vitro and has been used quite successfully in different surgical procedures to reduce operative blood loss [17].

Reconstructive spinal surgeries have been associated with significant blood loss which is a cause of morbidity. Previous studies reported antifibrinolytic medications could help reduce blood loss during surgery $[5,18,19]$. A recent study on the use of TXA in surgical paediatric patients cohered the results from previous studies on the significant blood loss reduction after using TXA as antifibrolytic agent [20]. However, there is still no report on the possible factors affecting the total blood loss apart from using TXA. The understanding the possible factors, apart from the use of TXA, provides very useful information on other components which could further control the amount of total blood loss at surgery. This study aimed to assess the efficacy of tranexamic acid (TXA) in reducing operative blood loss during posterior spinal fusion for the treatment of severe adolescent idiopathic scoliosis (AIS).

\section{Methods}

A retrospective cohort study was carried out on 90 female adolescents of 10 to 23 years old all undergoing posterior spinal fusion (PSF) procedures at an institution from year 2005 to 2010. They were recruited on a blind selection basis consecutively. Patients' drug allergy history to TXA was the only contraindication to its use. Otherwise, there was no other contraindication for any patients in receiving TXA. Patients who received intraoperative TXA were categorized into "TXA" group $(N=55)$, and "Control" group for non-receivers $(N=35)$. All patients showed normal blood urea nitrogen, blood creatinine level, bleeding time, prothrombin time (PT), activated partial thrombin time (APTT), international normalized ratio (INR), and serum platelet concentration. Patients with congenital scoliosis or neuromuscular disease or with combined anterior and posterior spinal fusions were excluded. Ethical approval was obtained from the ethics review board of the joint NTEC/CUHK joint-institutional ethics committee.

All patients underwent posterior spinal fusion (PSF) procedures with pedicle screw fixation after general anaesthesia by a skilled anaesthesiologist. The induction and maintenance of the general anaesthesia was accomplished using standard agents. All TXA group patients received an intravenous loading dose of $100 \mathrm{mg} / \mathrm{kg}$ TXA followed by a maintenance dose of $10 \mathrm{mg} / \mathrm{kg} / \mathrm{h}$, administered until the skin closure. No patient received preoperative auto pre-donation, intraoperative administration of TXA or other anti-fibrinolytics in the control group. No drain was inserted at the end of the surgical procedure. During the procedures, a special frame which decreased intra-abdominal pressure was used to minimize blood loss. Spinal cord function was monitored by somatosensory- and motor-evoked potentials. All patients received either donated blood or blood from cell saver. Postoperative blood transfusion was given when haemoglobin level dropped below $8 \mathrm{~g} / \mathrm{dl}$.

The blood loss was estimated by anaesthesia technician. The intraoperative blood loss was derived by measuring the intraoperative suction drainage and weighing the tapes and sponges. The basic demographic data, surgical statistics, blood loss, clotting capability and infusion of coagulation factors of the two groups were compared by Student's $T$-test. Sensitivity analysis on regression models was carried out to look for the possible risk factors (clotting capabilities, infusion of coagulation factors) affecting the total blood loss after controlling for confounding factors e.g., age at surgery, maximum major curve, number of segments fused, use of bone graft, length of surgery. Data analysis were carried out by IBM SPSS 20.0 (Armonk, New York). A two-sided $p$ value $\leq 0.05$ was considered statistically significant.

\section{Results}

This is a retrospective cohort study on 90 (TXA $=55$, Control $=35$ ) female patients aiming to look for the effect of the use of tranexamic acid on controlling blood loss in spinal corrective surgery in AIS. There were no significant differences between the TXA and control group in age (15.16 vs. $15.31 ; p=0.80$ ), mean body weight (Pre-op: $45.25 \mathrm{~kg}$ vs. $42.88 \mathrm{~kg}, p=0.20$; Post-op: $44.49 \mathrm{~kg}$ vs. $43.39 \mathrm{~kg}, p=0.65)$, though the TXA group had a higher pre-operative major curve (73.42 vs. 63.23; $p=0.01$ ) (Table 1). TXA group had significantly less intra-operative blood loss $(53.0 \%$ reduction) than the control group from the estimation by anaesthesia technician (1.8 L vs. $3.9 \mathrm{~L} ; p<0.01)$ (Table 2). Patients in the TXA group also received a significantly less volume of salvaged blood from cell saver $(0.6 \mathrm{~L}$ vs. $1.7 \mathrm{~L} ; p<0.01)$.

Different regression models were designed trying to explain the use of TXA on reducing the total blood loss after controlling for different kinds of confounders (Table 3). The statistical significances existed after controlling for possible confounding factors (age at surgery, number of segments fused, maximum major curve, use of bone graft, 
Table 1 Baseline characteristics of surgical patients with or without the use of TXA during surgery

\begin{tabular}{|c|c|c|c|}
\hline \multirow[t]{2}{*}{ Demographics } & \multicolumn{2}{|l|}{ Tranexamic acid } & \multirow[t]{2}{*}{$P$} \\
\hline & TXA $(N=55)$ & Control $(N=35)$ & \\
\hline \multicolumn{4}{|l|}{ Age } \\
\hline Mean \pm SD (Range) & $15.16 \pm 2.61(10-21)$ & $15.31 \pm 2.97(11-23)$ & 0.80 \\
\hline$\geq 12$ & $11(20.0)$ & $4(11.4)$ & 0.32 \\
\hline $13-14$ & 13 (23.6) & $15(42.9)$ & \\
\hline $15-16$ & $11(20.0)$ & $4(11.4)$ & \\
\hline $17-18$ & $15(27.3)$ & $8(22.9)$ & \\
\hline$\geq 19$ & $5(9.1)$ & $4(11.4)$ & \\
\hline Max major curve (Pre-op) & $73.42 \pm 11.75$ & $63.23 \pm 17.20$ & $<0.01$ \\
\hline \multicolumn{4}{|l|}{ Body weight (kg) } \\
\hline Pre-op & $45.25 \pm 8.96$ & $42.88 \pm 7.76$ & 0.20 \\
\hline Post-op & $44.49 \pm 8.14$ & $43.39 \pm 8.88$ & 0.65 \\
\hline \multicolumn{4}{|l|}{ Armspan (cm) } \\
\hline Pre-op & $157.04 \pm 8.99$ & $158.32 \pm 9.83$ & 0.54 \\
\hline Post-op & $156.04 \pm 9.40$ & $158.79 \pm 9.23$ & 0.35 \\
\hline \multicolumn{4}{|l|}{ Body height (cm) } \\
\hline Pre-op & $154.01 \pm 9.33$ & $155.36 \pm 7.70$ & 0.48 \\
\hline Post-op & $156.83 \pm 9.88$ & $157.76 \pm 8.82$ & 0.73 \\
\hline \multicolumn{4}{|l|}{ BMI $\left(\mathrm{kg} / \mathrm{m}^{2}\right)$} \\
\hline Pre-op & $19.03 \pm 3.53$ & $17.76 \pm 3.00$ & 0.08 \\
\hline Post-op & $18.07 \pm 2.77$ & $17.47 \pm 3.28$ & 0.48 \\
\hline Number of segments fused & $13.51 \pm 1.62$ & $12.14 \pm 2.79$ & 0.01 \\
\hline Number of pedicle screws inserted & $16.15 \pm 2.17$ & $16.29 \pm 4.34$ & 0.87 \\
\hline \multicolumn{4}{|l|}{ Bone graft } \\
\hline Allograft & $1(2.0)$ & $8(28.6)$ & $<0.01$ \\
\hline Autograft/Both & $49(98.0)$ & $20(71.4)$ & \\
\hline Unknown & 5 & 7 & \\
\hline Length of surgery & $436.71 \pm 122.53$ & $502.14 \pm 85.81$ & $<0.01$ \\
\hline
\end{tabular}

and length of surgery), without (model 1 to 4 ) or with (model 5 to 8 ) the clotting capabilities. The best model (model 6) explained that the use of TXA significantly decreased total blood loss by $794.3 \mathrm{ml}\left(\mathrm{r}^{2}=0.46, \mathrm{~B}=-5.25\right.$, $p<0.01)$ after controlling for maximum major curve and other clinical factors, clotting capabilities, and infusion of coagulation factor. There were no hemodynamic disturbances, apparent thromboembolic complications, or other drug complications associated with its use, such as disturbed colour vision, numbness or weakness, confusion, or allergic reactions major intraoperative complications for any of the treatment groups. No patient had clinical signs of deep venous thrombosis or renal complications.

\section{Discussion}

Pharmacological therapies are commonly used to reduce blood loss and blood transfusions in surgery. Tranexamic acid or TXA was previously shown to be as effective as other antifibrinolytics but at a much lower cost [21, 22]. The safety and efficacy of TXA are still controversial probably due to the difference in the dose of TXA used and type of surgery $[21,23]$. In this retrospective study, it was shown that TXA could significantly reduce blood loss with up to $53.0 \%$ reduction which is in concordance with some similar studies [19, 24, 25]. Intraoperative estimated blood loss was shown to be decreased by $56.8 \%$ for patients using TXA, reported from a comparative analysis of 106 consecutive adolescents undergoing PSF in Japan [14]. Moreover, contributing factors that could alter blood loss were included in regression analysis, thus proving the efficacy of TXA in reducing blood loss even after adjustment with possible confounding factors, clotting capabilities and infusion of coagulation factors. All the patients in this study showed no 
Table 2 Comparisons on the clotting capabilities, haemoglobin change, blood products transfused, and total blood loss in patients with or without using TXA

\begin{tabular}{lcr}
\hline Surgical parameters & Tranexamic acid & Control (N=35) \\
\cline { 2 - 3 } & TXA (N=55) & $11.32 \pm 1.04$ \\
\hline Clotting capability & $11.56 \pm 0.87$ & $1.05 \pm 0.06$ \\
$\quad$ Pre-op PT & $1.07 \pm 0.07$ & $37.92 \pm 4.83$ \\
Pre-op INR & $37.24 \pm 3.88$ & 0.18 \\
$\quad$ Pre-op APTT & & 0.46 \\
Haemoglobin change & $-2.99 \pm 1.58$ & $-3.33 \pm 1.56$ \\
$\quad$ Latest postop - preop & & 0.33 \\
Equivalent volume of whole blood/packed red blood cell transfused & $472.50 \pm 370.48$ & $891.67 \pm 358.35$ \\
$\quad$ Intra-operative & $150.00 \pm 256.04$ & $333.33 \pm 516.40$ \\
$\quad$ Post-operative & $575.36 \pm 412.25$ & $1684.26 \pm 1233.91$ \\
Volume of cell saver blood transfused back to patient (ml) & $194.41 \pm 125.19$ & $219.28 \pm 144.17$ \\
Volume of platelet transfused (ml) & $798.86 \pm 520.00$ & $863.18 \pm 458.48$ \\
Volume of fresh frozen plasma (FFP) transfused (ml) & $10.00 \pm 1.18$ & 0.04 \\
Latest post-operative hemoglobin level & $4.39 \pm 2.12$ & $0.66 \pm 0.75$ \\
Number of days for hemoglobin level reaching stable level post-operatively & $1826.11 \pm 1081.45$ & 0.59 \\
Total blood loss by anesthetist estimation (ml) & $135.62 \pm 78.10$ & $3.23 \pm 1.69$ \\
Total blood loss per segment (ml/segment) & $3889.60 \pm 2440.80$
\end{tabular}

TXA tranexamic acid used, Control none used, PT prothrombin time, INR international normalised ratio, APTT activated partial thromboplastin time

severe complications which demonstrated the safety of TXA.

The use of TXA in major paediatric surgery was proven to be better than the other commonly used antifibrinolytic agents e.g., aprotinin and aminocaproic acid $[20,21,23,26]$. Results from a recent randomized doubleblinded pilot study studying the efficacy of aminocaproic acid versus TXA in paediatric spinal deformity surgery concluded that TXA was associated with a lower allogenic transfusion requirement, less alteration in postoperative clotting studies, and a trend toward lower blood loss in paediatric posterior spinal fusion patients [24]. The cost of TXA is higher than aminocaproic acid, therefore, the use of TXA is excellent for long and complex surgeries e.g., scoliosis and surgeries with the use of autograft and long fusion levels [27]. Aprotinin was associated with severe side effects e.g., myocardial infraction, heart failure, and renal failure [28-31], although it was effective in reducing total blood loss after paediatric cardiac surgery [32]. Higher costs when using aprotinin make TXA a better option with similar efficacy. In this study, we clearly proved that the use of TXA in surgical scoliotic cases greatly reduced the volume of whole blood and blood from cell saver transfused back to the patients, although no comparison on the use of other antifibrinolytic agents were carried out because of the standard and consistency of clinical practice.

Studies tried to look for the factors other than the use of TXA affecting the total blood loss, however, no conclusion

Table 3 Sensitivity analysis on different linear regression models on the use of tranexamic acid, infusion of coagulation factors, and clotting capability on the total blood loss controlled for confounding factors

\begin{tabular}{|c|c|c|c|c|c|c|c|c|c|c|c|c|c|c|}
\hline Models & TXA & $\begin{array}{l}\text { Age at } \\
\text { surgery }\end{array}$ & $\begin{array}{l}\text { Number of } \\
\text { segments fused }\end{array}$ & $\begin{array}{l}\text { Max major } \\
\text { curve }\end{array}$ & $\begin{array}{l}\text { Bone } \\
\text { graft }\end{array}$ & $\begin{array}{l}\text { Length of } \\
\text { surgery }\end{array}$ & $\begin{array}{l}\text { Total FFP } \\
\text { transfused }\end{array}$ & $\begin{array}{l}\text { Total platelet } \\
\text { transfused }\end{array}$ & $\begin{array}{l}\text { PT } \\
\text { (pre-op) }\end{array}$ & $\begin{array}{l}\text { INR } \\
\text { (pre-op) }\end{array}$ & $\begin{array}{l}\text { APTT } \\
\text { (pre-op) }\end{array}$ & $r^{2}$ & B & $P$ \\
\hline$\overline{1}$ & $\checkmark$ & $\checkmark$ & $\checkmark$ & $\checkmark$ & $\checkmark$ & $\checkmark$ & & & & & & 0.31 & -4.98 & $<0.01$ \\
\hline 2 & $\checkmark$ & $\checkmark$ & $\checkmark$ & $\checkmark$ & $\checkmark$ & $\checkmark$ & $\checkmark$ & & & & & 0.45 & -5.25 & $<0.01$ \\
\hline 3 & $\checkmark$ & $\checkmark$ & $\checkmark$ & $\checkmark$ & $\checkmark$ & $\checkmark$ & & $\checkmark$ & & & & 0.44 & -5.25 & 0.05 \\
\hline 4 & $\checkmark$ & $\checkmark$ & $\checkmark$ & $\checkmark$ & $\checkmark$ & $\checkmark$ & $\checkmark$ & $\checkmark$ & & & & 0.27 & -3.99 & 0.14 \\
\hline 5 & $\checkmark$ & $\checkmark$ & $\checkmark$ & $\checkmark$ & $\checkmark$ & $\checkmark$ & & & $\checkmark$ & $\checkmark$ & $\checkmark$ & 0.32 & -5.26 & $<0.01$ \\
\hline 6 & $\checkmark$ & $\checkmark$ & $\checkmark$ & $\checkmark$ & $\checkmark$ & $\checkmark$ & $\checkmark$ & & $\checkmark$ & $\checkmark$ & $\checkmark$ & 0.46 & -5.25 & $<0.01$ \\
\hline 7 & $\checkmark$ & $\checkmark$ & $\checkmark$ & $\checkmark$ & $\checkmark$ & $\checkmark$ & & $\checkmark$ & $\checkmark$ & $\checkmark$ & $\checkmark$ & 0.48 & -4.93 & 0.10 \\
\hline 8 & $\checkmark$ & $\checkmark$ & $\checkmark$ & $\checkmark$ & $\checkmark$ & $\checkmark$ & $\checkmark$ & $\checkmark$ & $\checkmark$ & $\checkmark$ & $\checkmark$ & 0.39 & -4.01 & 0.15 \\
\hline
\end{tabular}

TXA, use of tranexamic acid (Yes/No), FFP fresh frozen plasma, PT prothrombin time, INR international normalised ratio, APTT activated partial thromboplastin time 
has been clearly made probably as a result of limited data collected for data analysis. Discussions on autologous blood transfusion and reinfusion of salvaged blood from cell saver machine being the causative factor have been introduced for over a decade $[6,20,25]$. Transfusion requirements and coagulation parameters were first introduced by Sethna et al. in a study with 44 children and adolescents undergoing scoliotic surgical corrections through comparative analyses [5]. Other factors like age, gender, and number of vertebral levels fused, were introduced in recent publications $[20,25]$. Length of hospital stay was discussed in a couple of reports, while this was the secondary clinical outcome of the use of TXA instead of being a factor on controlling total blood loss [33, 34]. At the ever-vigorous surgical environment, there are many factors which can affect the total blood loss, not solely dictated by the use of TXA, and these have to be controlled for us to draw a conclusion on the effect of TXA on controlling blood loss at surgery. This study collected information in possible confounding factors on total blood loss with the use of TXA at surgery in Chinese AIS patients, and confirmed the efficacy of TXA after controlling major confounding factors.

In this study, total blood loss estimated by anaesthesia technician was significantly reduced in patients using TXA at surgery. At the same time, volume of blood transfused from cell saver was also much reduced in TXA group. A recent study on the use of TXA in 49 surgical AIS patients undergoing posterior spinal fusion by a single surgeon showed similar findings on great decrease in total blood loss as of the present study [20]. The volume of blood transfused, however, did not appear to be affected [20]. In this study, the volume of salvaged blood from cell saver was much decreased in TXA group. Nonetheless, the total amount of blood loss and cell saver blood returned to the patients were relatively huge. These were because the spinal curvatures were large and the fusion levels were high. Similar results were obtained from surgeries on severe curvatures $[19,33]$. In summary. we have established a very tight transfusion protocol for AIS surgery, which makes the results different from the study from Lykissas and colleagues [20]. A recent randomized control trial was carried out to look for the efficacy of different antifibrinolytics in AIS. TXA and epsilon-aminocaproic acid effectively reduced estimated and actual blood loss, as well as declined in haematocrit after surgery compared with saline solution [25].

The present study also gives us an idea on the rate of blood loss decrease after using TXA at surgery with proper adjustment of confounding factors. Regarding to the transfusion rate being another important parameter evaluating the efficacy of antifibrinolytics, authors, the factors affecting the transfusion rate is mainly a surgeon-decisive issue, namely patient comorbidities, patient preference, preoperative blood donation, and clinical judgment [25]. Similar findings were found in another RCT published in Cochrane
Library [35]. A systematic review and meta-analysis on the use of intravenous TXA in spinal surgery carried out in China showed much reduced volume of blood loss and volume of transfused packed cells, although patient age was one of the study exclusion criteria making the analyses not totally applicable to present study [26]. An extended multicentre review on the use of different antifibrinolytic agents to reduce blood loss during vertebral column resection in paediatrics also confirmed the effectiveness of reduced estimated blood loss when using TXA during surgery after normalized to patient size and levels excised [19]. Similar observations are well-documented in many previous studies $[5,6,15,16,18,19,33-39]$. The present study is the first study on the evaluation of efficacy of TXA in Chinese AIS patients, with the novel findings of factors affecting total blood loss.

This is the first report on the use of TXA in surgical Chinese AIS patients. The factors affecting the total blood loss are derived by a series of sensitivity analysis through different regression models with the proper controlling of confounding factors.

\section{Limitations}

There are limitations we have to consider in this study. The small sample size and retrospective nature of this comparative study would limit the data generalizability. Our surgeons and anaesthetists had many years of experience in spinal surgery before beginning of this study, the ever-improving surgical skills over the years could influence the amount of total blood loss. The concern on the effect of the improvement of surgical skills on the amount of total blood loss was proven minimal after a closed monitoring of difference of total surgical blood loss over the study period. Yet a prospective dose-ranging study is still required to determine the optimal dose for spine surgery on patients with idiopathic scoliosis. To provide additional information on the efficacy and safety of TXA, multicentre randomized prospective analysis in the future is warranted.

\section{Conclusions}

Patients undergoing posterior spinal corrective surgery with the use of TXA showed much reduced total blood loss, reduced use of transfused blood, and much less cell saver blood transfused back to the patient. Using TXA at surgery, the total blood loss was decreased by $794.3 \mathrm{ml}$ after controlling for maximum major curve and other clinical factors, clotting capabilities, and infusion of coagulation factor. Use of tranexamic acid significantly reduced total surgical blood loss over corrective surgery for severe AIS patients, after adjusting for possible confounding factors, clotting capabilities, and infusion of coagulation factors. 


\section{Competing interests}

The authors declare that they have no competing interests.

\section{Authors' contributions}

BN conceived of the study, and participated in its design and coordination and helped to revise the manuscript. WWC performed the statistical analysis, drafted and revised the manuscript. AH revised the manuscript. AC helped design the study, carried out the data collection, and revised the manuscript. $T L$ drafted and revised the manuscript. JC conceived of the study, participated in its design, and revise the manuscript. All authors read and approved the final manuscript.

\section{Author details}

'Department of Orthopaedics \& Traumatology, Chinese University of Hong Kong, Shatin, Hong Kong. 'Department of Surgery, Prince of Wales Hospital, Shatin, Hong Kong. ${ }^{3}$ Department of Orthopaedics and Traumatology, The Chinese University of Hong Kong, Prince of Wales Hospital, Shatin, N.T., Hong Kong.

Received: 13 November 2014 Accepted: 13 September 2015 Published online: 05 October 2015

\section{References}

1. Guay J, Haig M, Lortie L, Guertin MC, Poitras B. Predicting blood loss in surgery for idiopathic scoliosis. Can J Anaesth. 1994;41:775-81.

2. Hur SR, Huizenga BA, Major M. Acute normovolemic hemodilution combined with hypotensive anesthesia and other techniques to avoid homologous transfusion in spinal fusion surgery. Spine (Phila Pa 1976). 1992;17:867-73.

3. Hu SS. Blood loss in adult spinal surgery. Eur Spine J. 2004;13 Suppl 1:S3-5

4. Nuttall GA, Horlocker TT, Santrach PJ, Oliver WC, Dekutoski MB, Bryant S. Predictors of blood transfusions in spinal instrumentation and fusion surgery. Spine (Phila Pa 1976). 2000;25:596-601.

5. Sethna NF, Zurakowski D, Brustowicz RM, Bacsik J, Sullivan LJ, Shapiro F. Tranexamic acid reduces intraoperative blood loss in pediatric patients undergoing scoliosis surgery. Anesthesiology. 2005;102:727-32.

6. Neilipovitz DT, Murto K, Hall L, Barrowman NJ, Splinter WM. A randomized trial of tranexamic acid to reduce blood transfusion for scoliosis surgery. Anesthe Analg. 2001;93:82-7.

7. Ho KM, Ismail $\mathrm{H}$. Use of intravenous tranexamic acid to reduce allogeneic blood transfusion in total hip and knee arthroplasty: a meta-analysis. Anaesth Intensive Care. 2003;31:529-37.

8. Florentino-Pineda I, Blakemore LC, Thompson GH, Poe-Kochert C, Adler P, Tripi P. The Effect of epsilon-aminocaproic acid on perioperative blood loss in patients with idiopathic scoliosis undergoing posterior spinal fusion: a preliminary prospective study. Spine. 2001;26:1147-51.

9. Florentino-Pineda I, Thompson GH, Poe-Kochert C, Huang RP, Haber LL, Blakemore LC. The effect of amicar on perioperative blood loss in idiopathic scoliosis: the results of a prospective, randomized double-blind study. Spine. 2004:29:233-8.

10. Thompson GH, Florentino-Pineda I, Poe-Kochert C. The role of amicar in decreasing perioperative blood loss in idiopathic scoliosis. Spine. 2005:30:594-9.

11. Thompson GH, Florentino-Pineda I, Armstrong DG, Poe-Kochert C. Fibrinogen levels following Amicar in surgery for idiopathic scoliosis. Spine. 2007:32:368-72.

12. Thompson GH, Florentino-Pineda I, Poe-Kochert C, Armstrong DG, Son-Hing J. Role of Amicar in surgery for neuromuscular scoliosis. Spine. 2008:33:2623-9.

13. Thompson GH, Florentino-Pineda I, Poe-Kochert C, Armstrong DG, Son-Hing JP. The role of Amicar in same-day anterior and posterior spinal fusion for idiopathic scoliosis. Spine. 2008;33:2237-42.

14. Yagi M, Hasegawa J, Nagoshi N, lizuka S, Kaneko S, Fukuda K, et al. Does the intraoperative tranexamic acid decrease operative blood loss during posterior spinal fusion for treatment of adolescent idiopathic scoliosis? Spine (Phila Pa 1976). 2012;37:E1336-42.

15. Grant JA, Howard J, Luntley J, Harder J, Aleissa S, Parsons D. Perioperative blood transfusion requirements in pediatric scoliosis surgery: the efficacy of tranexamic acid. J Pediatr Orthop. 2009;29:300-4.

16. Schouten ES, van de Pol AC, Schouten AN, Turner NM, Jansen NJ, Bollen CW. The effect of aprotinin, tranexamic acid, and aminocaproic acid on blood loss and use of blood products in major pediatric surgery: a meta-analysis. Pediatr Crit Care Med. 2009;10:182-90.

17. Lecker I, Wang D-S, Romaschin AD, Peterson M, Mazer CD, Orser BA. Tranexamic acid concentrations associated with human seizures inhibit glycine receptors. J Clin Invest. 2012;122:4654-66.

18. Shapiro F, Zurakowski D, Sethna NF. Tranexamic acid diminishes intraoperative blood loss and transfusion in spinal fusions for duchenne muscular dystrophy scoliosis. Spine. 2007;32:2278-83.

19. Newton PO, Bastrom TP, Emans JB, Shah SA, Shufflebarger HL, Sponseller $P D$, et al. Antifibrinolytic agents reduce blood loss during pediatric vertebral column resection procedures. Spine (Phila Pa 1976). 2012;37:E1459-63.

20. Lykissas MG, Crawford AH, Chan G, Aronson LA, Al-Sayyad MJ. The effect of tranexamic acid in blood loss and transfusion volume in adolescent idiopathic scoliosis surgery: a single-surgeon experience. J Child Orthop. 2013;7:245-9.

21. Danninger T, Memtsoudis SG. Tranexamic acid and orthopedic surgery-the search for the holy grail of blood conservation. Ann Transl Med. 2015;3:77.

22. Sepah YJ, Umer M, Ahmad T, Nasim F, Umer Chaudhry M, Umar M. Use of Tranexamic acid is a cost effective method in preventing blood loss during and after total knee replacement. J Orthop Surg Res. 2011;6:22-2.

23. Li Z-J, Fu X, Xing D, Zhang H-F, Zang J-C, Ma X-L. Is tranexamic acid effective and safe in spinal surgery? A meta-analysis of randomized controlled trials. Eur Spine J. 2013;22:1950-7.

24. Halanski MA, Cassidy JA, Hetzel S, Reischmann D, Hassan N. The efficacy of amicar versus tranexamic acid in pediatric spinal deformity surgery: a prospective, randomized, double-blinded pilot study. Spine Deformity. 2014:2:191-7.

25. Verma K, Errico T, Diefenbach C, Hoelscher C, Peters A, Dryer J, et al. The relative efficacy of antifibrinolytics in adolescent idiopathic scoliosis: a prospective randomized trial. J Bone Joint Surg Am. 2014;96:e80.

26. Yang B, Li H, Wang D, He X, Zhang C, Yang P. Systematic review and metaanalysis of perioperative intravenous tranexamic acid use in spinal surgery. PLoS One. 2013;8:e55436.

27. Vlessides M. Price, not performance, separates two blood-sparing drugs. In "In the news", vol. 37: General Surgery News; 2010. http://www anesthesiologynews.com/ViewArticle.aspx?d_id=1\&a_id=15735. Accessed 30 September 2015.

28. Mangano DT, Rieves RD, Weiss KD. Judging the safety of aprotinin. N Engl J Med. 2006;355:2261-2.

29. Mangano DT, Miao Y, Vuylsteke A, Tudor IC, Juneja R, Filipescu D, et al. Mortality associated with aprotinin during 5 years following coronary artery bypass graft surgery. JAMA. 2007;297:471-9.

30. Mangano DT, Tudor IC, Dietzel C, Group MSoPIR, Foundation IRaE. The risk associated with aprotinin in cardiac surgery. N Engl J Med. 2006;354:353-65.

31. Ferguson TB. Aprotinin-are there lessons learned? JAMA. 2007;297:527-9.

32. Arnold DM, Fergusson DA, Chan AK, Cook RJ, Fraser GA, Lim W, et al. Avoiding transfusions in children undergoing cardiac surgery: a meta-analysis of randomized trials of aprotinin. Anesth Analg. 2006;102:731-7.

33. Dhawale AA, Shah SA, Sponseller PD, Bastrom T, Neiss G, Yorgova P, et al. Are antifibrinolytics helpful in decreasing blood loss and transfusions during spinal fusion surgery in children with cerebral palsy scoliosis? Spine. 2012;37:E549-55.

34. Verma K, Errico TJ, Vaz KM, Lonner BS. A prospective, randomized, doubleblinded single-site control study comparing blood loss prevention of tranexamic acid (TXA) to epsilon aminocaproic acid (EACA) for corrective spinal surgery. BMC Surg. 2010;10:13.

35. Tzortzopoulou A, Cepeda MS, Schumann R, Carr DB. Antifibrinolytic agents for reducing blood loss in scoliosis surgery in children. Cochrane Database Syst Rev. 2008;3:CD006883.

36. Xu C, Wu A, Yue Y. Which is more effective in adolescent idiopathic scoliosis surgery: batroxobin, tranexamic acid or a combination? Arch Orthop Trauma Surg. 2012;132:25-31.

37. Palmer GM, Pirakalathanan $P$, Skinner AV. A multi-centre multi-national survey of anaesthetists regarding the range of anaesthetic and surgical practices for paediatric scoliosis surgery. Anaesth Intensive Care. 2010;38:1077-84.

38. Bednar DA, Bednar VA, Chaudhary A, Farrokhyar F. Tranexamic acid for hemostasis in the surgical treatment of metastatic tumors of the spine. [Erratum appears in Spine. 2006 Jul 15;31(16):1866 Note: Farroukhyar, Forough [corrected to Farrokhyar, Forough]]. Spine. 2006;31:954-7.

39. Guay J, de Moerloose P, Lasne D. Minimizing perioperative blood loss and transfusions in children. Can J Anaesth. 2006;53:S59-67. 